\title{
Verifying data for the implementation of the water release module of the WAS program
}

\author{
A Jansen van Vuuren ${ }^{1 *}$, E Pretorius ${ }^{2}$ and N Benadé ${ }^{3}$ \\ ${ }^{1}$ Central University of Technology, Free State, Private Bag X20539, Bloemfontein 9300, South Africa \\ ${ }^{2}$ Central University of Technology, Free State, Private Bag X20539, Bloemfontein 9300, South Africa \\ ${ }^{3}$ NB Systems cc, PO Box 15102, Sinoville, 0129 South Africa
}

\begin{abstract}
The Water Administration System (WAS) is designed to be a management tool for irrigation schemes and water control offices that want to manage their water accounts and supply water to clients through canal networks, pipelines and rivers. The ultimate aim of WAS is to optimise irrigation water management and minimise management-related distribution losses in irrigation canals. This research projects focused on the implementation of the water release module of the WAS program at the Vaalharts irrigation scheme. The WAS consists of four modules that are integrated into a single program that can be used on a single PC or a multi-user environment. The four modules are an administration module, a water release module, water accounts module and a water request module. The first three modules are already implemented at Vaalharts, while module four is implemented only partially. This module links with the water request module and calculated water releases for the main canal and all its branches allowing for lag times and any water losses and accruals. To precisely calculate this water release, accurate data is needed to ensure that the correct volume of water is released into the canal network. This can be done by verifying existing data with field data. To optimise the management of the irrigation scheme the fully implemented WAS program need to be installed and running at the scheme. A series of data and calculation verifications need to be executed. The exercise will show the adequacy and correctness of the available database WAS uses to do the release calculation from. This will ensure improved management of the irrigation scheme, catchment and water resource sustainability. It is planned that the information generated from this project will be used in the compilation of integrated catchment management information system, currently underway at the Central university of Technology, Free State, South Africa. It is for this reason that all data should be verified, as trustworthy results and service through management can then be offered to the community and irrigation area.
\end{abstract}

Keywords: water administration, irrigation, water distribution, canal network, water utilisation, agricultural, reach distances, lag time, discharge, water, demand management

\section{Introduction}

The slogan of the Israeli Water Directorate which states that '...no man may waste a single drop of water that another man may turn into bread...' could be applied to the current situation in South Africa. In general, South Africa is considered a waterscarce country (Ayoda, 1988). Water restrictions and the scarcity of water in South Africa have taught us to use water sparingly from an early age. The National Water Act, Act 36 of 1998 (South Africa, 1998a) also emphasises this issue of water usage and constantly refers to conservation control and equitable distribution of water (South Africa, 1998b). Conferences, symposiums and workshops therefore play a vital role in defining and planning sustainable resource management (Cousens, 1998). Water resources need to be controlled by a well-organised managerial body, which will form the basis for effective distribution of the resource.

According to Görgens et al. (1998) water resource management in South Africa has been transformed significantly as a result of the following two events:

- The democratisation of the Republic of South Africa

- The need for new approaches to water resource management due to misuse and mismanagement of available water resources.

This paper was originally presented at the 2006 Water Institute of South Africa (WISA) Biennial Conference, Durban, South Africa, 21-25 May 2006.

* To whom all correspondence should be addressed.

畐+2751 430-3111; fax:+2751 447-9403; e-mail:arnojvv@africon.co.za
Simplifying the management process is important, as it could be a lengthy and difficult program. Supplying the controlling body with a management tool will increase the degree of conservation, control, distribution and efficiency of water resource use. The Water Administration System (WAS) has been implemented at the Vaalharts Waters User's Association (VHWUA) in order to manage water resources effectively. The WAS is designed as a management tool for irrigation schemes and water management offices to manage their accounts and to supply water to clients through canal networks, pipelines and rivers (Benadé, 2001). The WAS consists of four modules that are integrated into a single program that can be used on a single PC or a multi-user environment. The PC network system is currently in use at the VHUWA. The four modules can be implemented partially or as a whole, depending on the requirements of the specific scheme or office. The four modules are:

- An administration module

- A water request module

- A water accounts module

- A water release module.

The first three modules have been fully implemented at Vaalharts, while the water release module has been partially implemented. This module links with the water administration and water request modules and calculates water releases for the main canal and all its branches, allowing for lag times, water losses and accruals. The four modules can be implemented partially or as a whole, depending on the requirements of the specific 


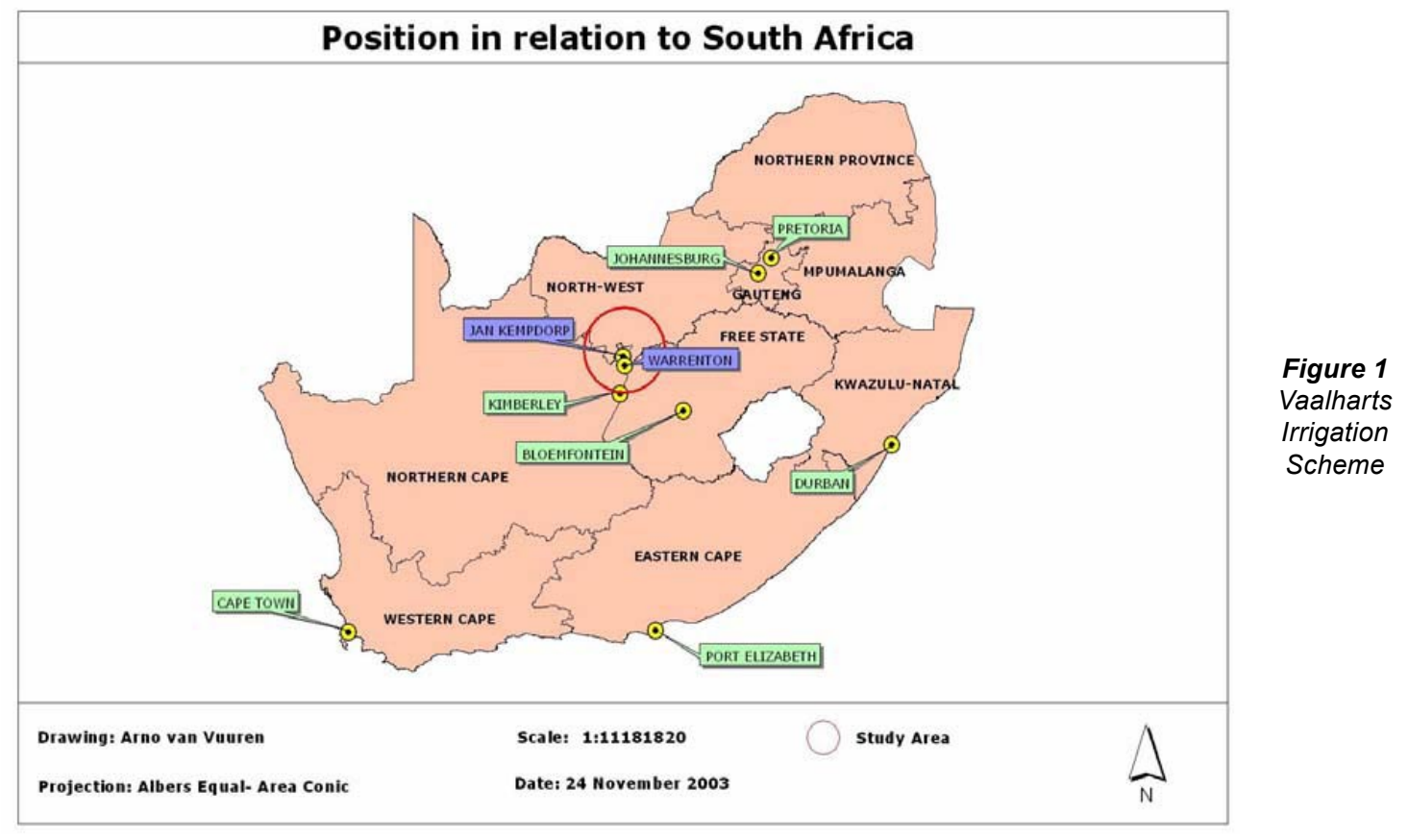

scheme or office (Benadé, 2001), although the Vaalharts Irrigation Scheme requires the full operation of the WAS program. This implies that the final module (water release module) must be fully implemented and calibrated to take over from the current means of water release calculation.

\section{Methodology}

The study was conducted in the VHWUA, which is located in the Warrenton/Jan Kempodorp/Hartswater district in the Northern Cape, South Africa. The head office in Jan Kempdorp, administers the VHWUA (Fig. 1). The main purpose of the study is to fully implement the WAS program and more specifically the water release module. In order to achieve the cycle of data verification, exercises need to be completed. In the process of capturing data, detail such as the cross-sectional properties, positioning of sluices and pumps, canal slopes, as well as canal capacities must be presented in a layout of the canal network. Once this has been done it is possible to realise the aims of the study. Irrigation scheme management will thus be optimised and the benefits can be applied from the managerial properties? Not clear what is meant of the WAS program.

All four of the WAS modules will contribute towards the successful completion. The WAS Program, as designed by $\mathrm{N}$ Benadé, bases all its calculations on the Manning flow equation (Benadé, 2001). It is evident thus far that a variety of geometrical information regarding the canal is needed to calculate the release. Since the main purpose of the project described in thus study is to implement the release module of the WAS program, it was crucial to verify all information and data, as all the calculations were based on this database. Four general methods to verify information and data were used, namely:

- Meetings/ consultations with farmers, technicians, etc.

- Engineering design drawings

- Mathematical calculations

- Collection of field data.

A $5^{\text {th }}$ method was also applied. In this method calculated results were compared to one another in order to interpret the results and findings of calculations. This method is the most impor- tant as it will indicate the effectiveness and validity of the WAS calculation procedure.

\section{Results and discussion}

\section{Meetings and consultations}

On 27 August 2002 meetings and consultations were initiated with some of the water control officers and other key role-players of the community. A general planning meeting was held where various aspects of the WAS program were explained as well as the reasons why various implementations needed to take place. It was important to inform these key role-players, to give them a better understanding of the motivation for the project and to enable them to delegate instructions to subordinates.. At this meeting some important information was gathered. From this information decisive decisions could be made for further assumptions. The information included:

- The attitude of the community towards the use of the model

- Community's knowledge of the WAS program

- Areas where data should be collected

- Type of data to be collected

- Methods of data collection

- The best approach to be used with regard to the community.

\section{Engineering design drawings}

An alternative approach is to use the design drawings of the structural engineer. The data are compared with corresponding data on the canal layout on the computer. The latter method is the most applicable as initial design intentions are stipulated in the drawings. Specifically for this type of data set, engineering drawings proved to be a satisfactory means of data verifications. Data verified using this method proved to be correct and valid. Data that were previously unavailable were updated using this method.

\section{Mathematical calculations}

The objective of this exercise was to compare the flow discharge from the two canals and then to make assumptions regarding 

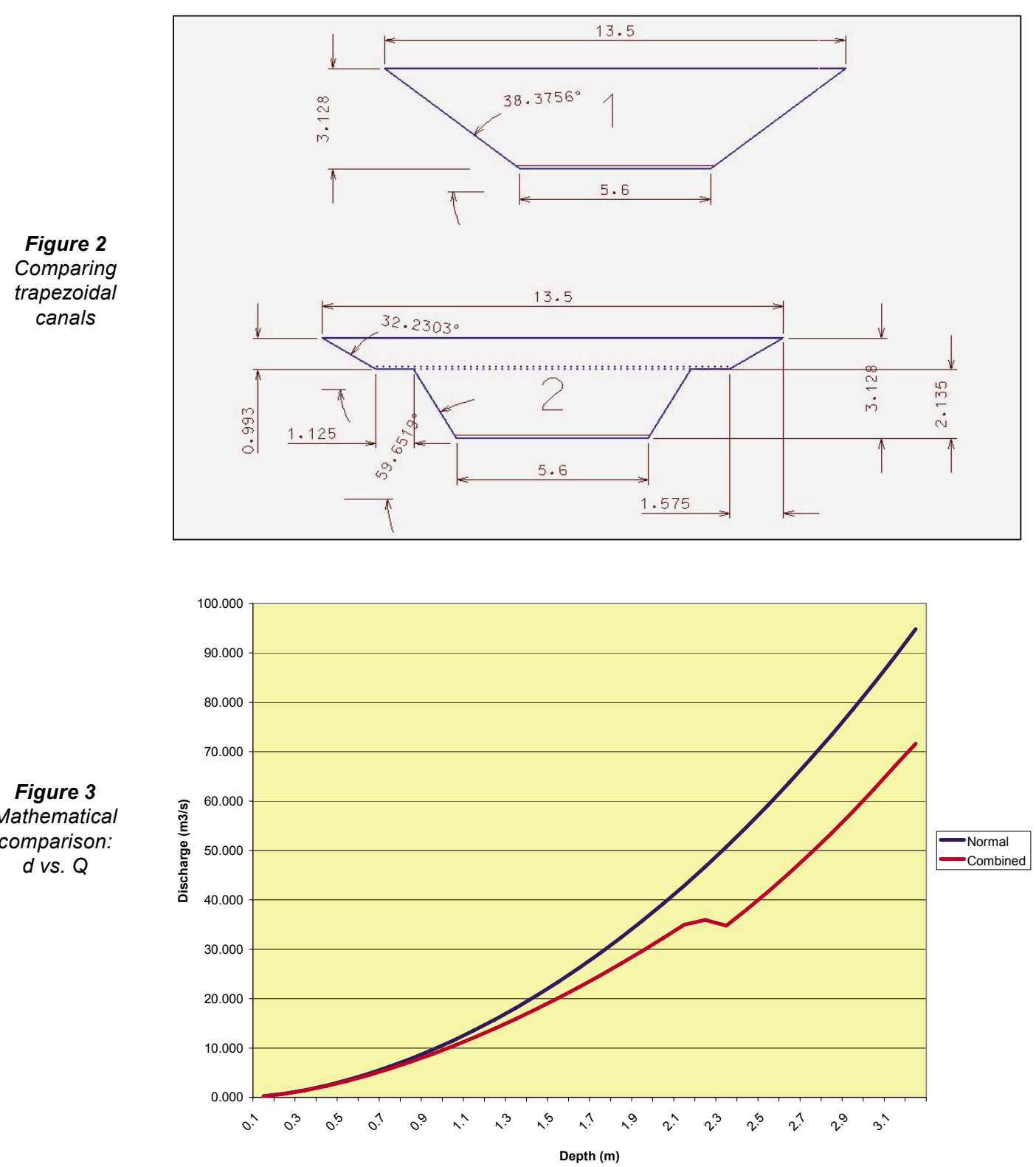

which canal section type to use in the WAS (Fig. 2). Using the Manning formula, cumulative values for discharge were calculated for both canals in each instance. The flow rate was calculated for increases in depth of $100 \mathrm{~mm}$ for each increment up to the full depth of $3.128 \mathrm{~m}$. The user is now able to choose between the two canals according to scheme demands and other assumptions.

The combined trapezoidal canal delivers a discharge of $19.13 \mathrm{~m}^{3} / \mathrm{s}$ less than the normal trapezoidal canal. If the combined canal is in operation at the scheme, but the normal canal shape is used as the basis for calculation, problems might occur. This exercise proves that the wrong volume of water is calculated. Figure 3 shows the comparison when calculating the discharge in relation to depth and comparing it to each other. The entire exercise regarding the mathematical comparison of the two canal sections proved to be a valuable input, particularly with regard to optimisations of the canal calculation procedure. One of the benefits of the WAS program is to improve water utilisation (Benadé, 2001).

\section{Collection of field data}

Satisfactory results were obtained by collecting data on site in the field and comparing these to existing data on the canal layout in the WAS program. The majority of data were collected using this method. Once again Community Canal 4A was used to illustrate the desired results. As discussed before, data from the canal layout was used to base the water release calculations on. It can clearly be seen that data collected in the field should correspond with the actual computer data.

Field work thus proved that the data for Community Canal $4 \mathrm{~A}$ were different from those of the actual canal layout. This implies that data on the computer should be updated regularly so that only the correct and verified data are used. Applying this method randomly to other sections of the canal will result in a general idea of all the correct and incorrect data. The most desired scenario would be to verify each and every turnout on the scheme using this method. Due to time and other constraints, however, it was not possible in this study. Picture 1 shows some of the methods used to verify canal geometry and some of the 


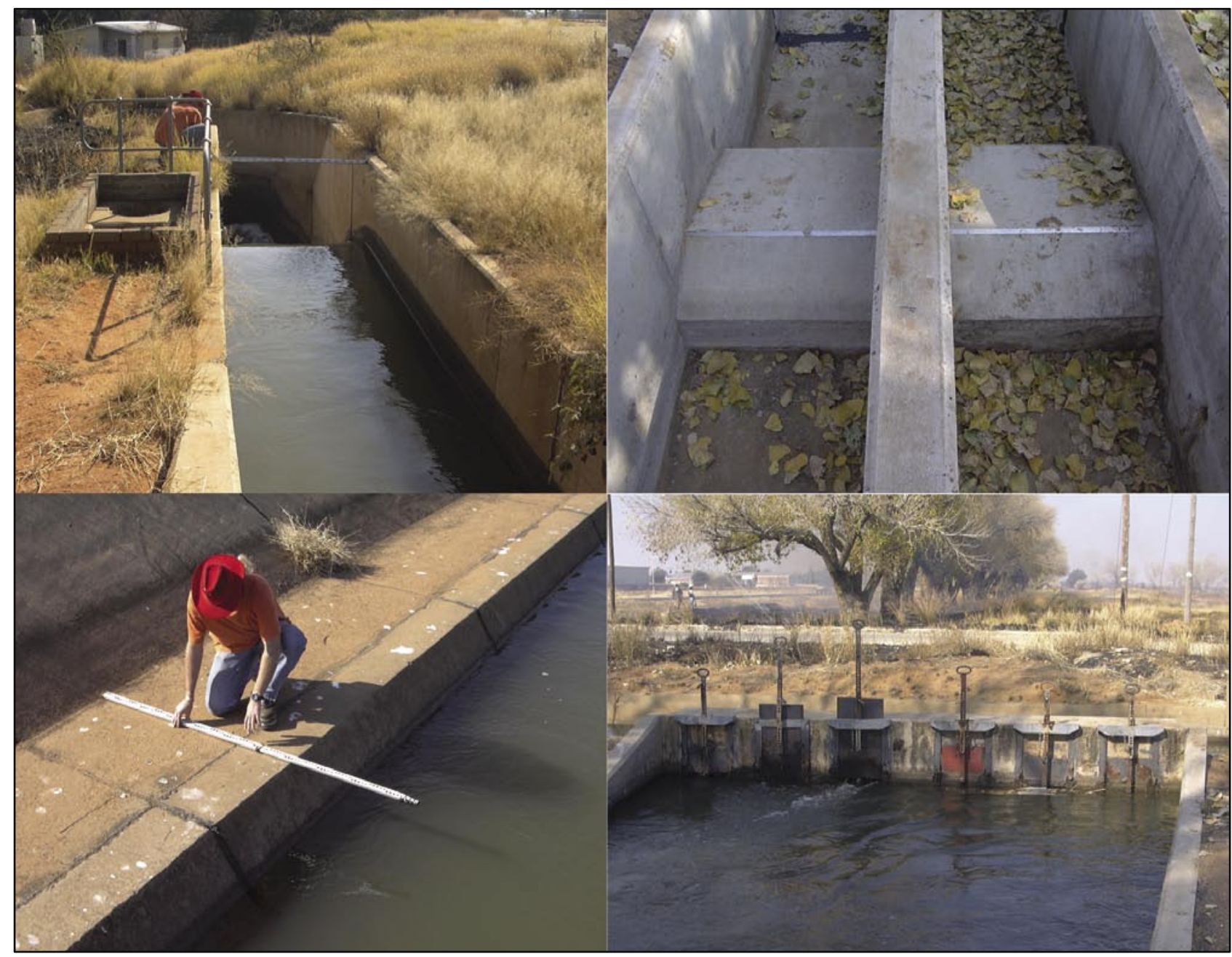

Picture 1

Structures to be verified for correctness

\begin{tabular}{|c|c|c|c|c|c|c|}
\hline & \multicolumn{6}{|c|}{$\begin{array}{c}\text { TABLE } 1 \\
\text { Calculation results for Cycle } 3\end{array}$} \\
\hline & \multicolumn{2}{|l|}{ Period 14} & \multicolumn{2}{|l|}{ Period 30} & \multicolumn{2}{|l|}{ Period 46} \\
\hline & Description & Volume & Description & Volume & Description & Volume \\
\hline \multirow{2}{*}{ VHWUA } & Without losses & 138600 & Without losses & 241200 & Without losses & 279000 \\
\hline & With losses (Excel) & 223692 & With losses (Excel) & 359412 & With losses (Excel) & 418803 \\
\hline \multirow{4}{*}{ WAS } & Without losses & 138600 & Without losses & 241200 & Without losses & 279000 \\
\hline & With losses (WAS) & 232968 & With losses (WAS) & 355899 & With losses (WAS) & 397506 \\
\hline & $\%$ diff- without losses & 0.0 & $\%$ diff- without losses & 0.0 & $\%$ diff- without losses & 0.0 \\
\hline & $\%$ diff- with losses & 4.1 & $\%$ diff- with losses & -1.0 & $\%$ diff- with losses & -5.1 \\
\hline
\end{tabular}

structures to be verified. This proved to be valuable for further verification methods.

\section{Excel vs. WAS comparison/evaluation}

At the beginning of this chapter the hypothesis was stated that if all verification could be done successfully on a singe feeder, delivering satisfactory results and proving the calculation procedure correct, the same procedure could then be applied to all the other canals in the network. For this reason F4 was singled out and the $3^{\text {rd }}$ cycle of calibrations and calculations was executed. Table 1 shows the calculation results after the $3^{\text {rd }}$ cycle of calibrations. The percentage difference (as indicated in red) for the volumes without losses is $0 \%$ (calculation comparison test) as the same calibration values indicated reflect only the requested amount of water without any losses. This corresponds with the Excel values, thus proving them correct. Any differences still encountered indicate the difference.

Figure 4 graphically shows the difference between the WAS calculation results and the EXCEL calculation results. It may 




therefore be concluded that all necessary data were updated and verified correctly as final calculations proved to correspond. The verified dataset can now be applied to the VHWUA. Since F4 was successfully validated, it may be assumed that the same method of validations and calibrations can be applied to any of the other feeder canals in the VHWUA. The rest of the canal network could therefore be built into this basis of data verification. By completing this exercise, trustworthy results can be obtained and the WAS program can be implemented fully.

\section{Conclusion}

At the beginning of the project the first three modules were implemented on the scheme while the $4^{\text {th }}$, the water release module, was still outstanding. Presently, however, Jan Kempdorp operates the Vaalharts Irrigation Scheme with all four modules but the release module is not in use at the moment Author: Please rephrase. Although the $4^{\text {th }}$ module has not been completed due to ongoing calibrations and validations, it is anticipated that all data on the program can be verified and proved by the same method. The correct water release volume can therefore be calculated. As with all other similar computer-based managerial programs, a time of calibration is needed to evaluate and verify the performance of the system in operation.

The WAS has already been implemented on a number of other irrigation schemes in South Africa with satisfactory results. Some schemes use the WAS only for accounts, while others use it for administrator benefits. The intention is to implement the WAS fully at the VHWUA, making it the water management tool of the scheme. The VHWUA also lends itself to future developments of the WAS and water management. With the current water agreements between South Africa and Lesotho, and with the next phase in the Lesotho Highlands Water Project about to start, South Africa will definitely have more water available for irrigation. This will also be in line with new proposed community projects where agriculture needs to be improved (WRC, 2000). An adequate water supply is a much-needed commodity for any upcoming farmer. Certain assumptions can therefore be made that management tools such as the WAS program will always be in demand to deal with and manage new irrigation schemes. Other possibilities include the scheduling of water usage (Benadé et al., 2002). There are certainly application possibilities for new or already established irrigation schemes that need a computer-based management tool.

The WAS is most certainly a real-time possibility at the VHWUA. It offers all the benefits and provides in every need of the management office. Once the program is in full use, it should be implemented on a continuous basis, i.e. the scheme should not revert back to the old method of calculation. The more the program can be run on a continuous basis, the more satisfactory and trustworthy results can be obtained. The WUA must use correct and updated data in their weekly calculations. The validity of information and results can only be seen with time, thus verification and error checking will provide results that are correct and that can be used for years to come.

Sustainable water resource utilisation can only be achieved through proper management. Applying the most effective management procedure will ensure a cost effective and optimised process at the VHWUA. As the WAS can definitely calculate the correct release volume of water into a canal or river system, it is the ideal package to implement in any irrigation board or water users' association.

\section{Reference}

AYOADA JO (1988) Tropical Hydraulics and Water Resources ( $1^{\text {st }}$ edn.). London. Macmillan Publishers. 189-239.

BENADÉ N, ANNANDALE GW and JOVANOVIC NZ (2002) The Development of an Integrated Information System for Irrigation Water Management Systems for Irrigation Water Management using WAS, SWB and RISKMAN Computer Models. WRC Report No. 946/1/02. Water Research Commission, Pretoria, South Africa.

COUSENS DWH (1998) Surface Water Resources of South Africa: Research Needs. WRC Report No. AV 1/88. Water Research Commission, Pretoria, South Africa.

GÖRGENS A, PEGRAM G, UYS M, GROBICKI A, LOOTS L, TANNER A and BENGU R (1998) Guidelines for Catchment 
Management to Achieve Integrated Water Resource Management in South Africa. WRC Report No. KV 108/98. Water Research Commission, Pretoria, South Africa.

SOUTH AFRICAN GOVERNMENT ONLINE Government Communications (1998a) White Paper on a National Water Policy for South Africa. Pretoria, South Africa. Available from: http://www.gov.za whitepaper/1997/water.pdf (Accessed October 2003).
SOUTH AFRICAN GOVERNMENT (1998) National Water Act, Act 36 of 1998b. Pretoria: Government Printers.

WATER RESEARCH COMMISSION (WRC) (2000) Improving Agricultural Water Management. WRC Report No TT 127/00. Pretoria. Water Research Commission, Pretoria. 